\title{
ENVIRONMENTAL PERFORMANCE OF PALM- BASED METHYL ESTER SULPHONATES PRODUCTION USING LIFE CYCLE APPROACH
}

NOORAZAH ZOLKARNAIN*; ZULINA ABD MAURAD*; RAZMAH, G and HAZIMAH, A H*

\begin{abstract}
Palm-based methyl ester sulphonates (MES) derived from palm oil through sulphonation process offer an interesting alternative to petroleum-based surfactants. This study was carried out to identify any potential environmental impacts that could be associated with the production of palm-based MES. Data on pilot plant production were obtained from the Malaysian Palm Oil Board (MPOB)'s MES pilot plant with $20 \mathrm{~kg}$ $h r^{-1}$ capacity. Life cycle assessment (LCA) performance was based on representative inventory data of MES processes for three years of production. The results were analysed using Eco-indicator 99 methodology operated under SimaPro version 8.0.2 software. The single score results showed that the main impact contributors for MES production at pilot plant scale were from production of methyl ester, steam and methanol. Based on weighted score, the most significant impact categories from this production were fossil fuels, respiratory inorganics and climate change. However, there was no significant impact value on land use category since this study was conducted with best management practices in oil palm plantation in Malaysia. From this study, it can be concluded that the production of MES at pilot plant using the best approach used in the oil palm industry are more sustainable and environmental-friendly.
\end{abstract}

Keywords: alpha-sulphonated methyl ester, palm-based surfactant, palm oil, anionic surfactant, detergent, life cycle assessment.

Date received: 1 July 2015; Sent for revision: 24 July 2015; Received in final form: 9 November 2015; Accepted: 13 January 2016.

\section{INTRODUCTION}

Detergents and household cleaning products contain surfactant(s), the main ingredient that plays a pivotal role in the overall cleaning process. Before the oil crisis in the 1970s, detergent manufacturers generally used linear alkyl benzene sulphonates (LAS), alkyl sulphates (AS) and alpha olefin sulphonates (AOS) from petroleum as surfactants in detergent. However, when oil crisis happened in the 1970s, detergent manufactures have shown interest in natural fat and oil-based surfactants,

\footnotetext{
* Malaysian Palm Oil Board,

6 Persiaran Institusi, Bandar Baru Bangi,

43000 Kajang, Selangor, Malaysia

E-mail: azah@mpob.gov.my
}

rather than those of petroleum-based. Natural feedstocks from renewable resources, such as oleochemical-based alcohols and methyl esters, offer interesting possibilities as surfactants. In addition, issues pertaining to environmental concerns, mildness, natural, cost effectiveness and sustainable development have led the search for new surfactants from these renewable resources.

Palm-based methyl ester sulphonates (MES) or also known as palm-based alpha-sulphonated methyl ester ( $\alpha$-SME), is an oleochemical-based anionic surfactants derived from palm oil-based methyl ester route instead of the fatty alcohol route. It has good surface-active properties and excellent detergency performance when used in laundry detergent (main ingredient), good biodegradability 
and is less sensitive to water hardness (Razmah and Salmiah, 2004; Razmah et al., 2006). The detergency of MES from palm stearin and palm fatty acid distillates was found to be similar or comparable to LAS and fatty alcohol sulphates (FAS) (Salmiah et al., 1998).

MES is relatively new to the surfactant industry and is normally used together with LAS as surfactants in laundry detergents in Malaysia (Letchumi and Sumiani, 2014). To date, several MES producers have expanded their production all over the world. Table 1 shows the global MES producers as reported in 2012 (Zulina, 2013). As reported by Grand View Research Inc. (2014), MES was the largest consumed biosurfactant, accounting for $33.26 \%$ of the $344000 \mathrm{t}$ of biosurfactant global market in 2013. This scenario was the result of the superior properties of MES in terms of foaming and stability as compared to other surfactants that make it ideal for use in household detergents.

In MPOB, research on MES had started in the early 1980s. This research is in line with MPOB's strategic direction, i.e. to add value to palm oil and to find possible new applications of oleochemicals, such as a surfactant in cleaning products. MPOB has successfully produced high quality palm-based MES at pilot plant scale and used it as an active ingredient (surfactant) in the production of liquid and powder detergents (Zulina et al., 2006).

As MES has a bright future and potential of gaining big market share in the surfactant industry, it is necessary to assess the impacts of its production on environment. The sustainability of MES production may be assessed using a life cycle assessment (LCA) approach. LCA is a common environmental management tool and a good analytical tool for assessing and optimising the environmental quality of a production system over the whole life cycle. In the oil palm industry, the LCA approach is not a new thing since several LCA studies on palm oil have been conducted using this approach in order to overcome all the issues on sustainability and environment. LCA becomes a good tool to help the industry to promote their products and to give a good perspective to the oil palm industry.

In 2010, MPOB established a full LCA study of the Malaysian oil palm industry including nursery, plantation, milling, refinery and palm biodiesel (Halimah et al., 2010; Zulkifli et al., 2010; Vijaya et al., 2010; Yew et al., 2010; Puah et al., 2010). Through these studies, the sustainability of oil palm supply chain with the best scenario and approach such as biogas capture and continued land use has been proven.

Previously, study done by the Lion Corporation of Japan (Yutaka, 2009) has proven that the use of MES contributed $51 \%$ reduction of the carbon dioxide emission. The carbon dioxide emission was reduced by about $27 \mathrm{~kg} \mathrm{yr}^{-1}$ for one Japanese household, where the laundry amount was about $32 \mathrm{~kg}$ per week. Letchumi and Sumiani (2014) also confirmed that MES is more environmental-friendly than LAS with equal washing performance. However, the data of this study were mainly generated from SimaPro database and Ecoinvent unit process which is not from plant operation.

At present, numerous LCA studies have been conducted on the production of MES. However, most of the LCA studies on MES production were conducted without using proper LCI data from oil palm industry. Therefore, this study was performed using established LCI data from oil palm industry

TABLE 1. GLOBAL METHYL ESTER SULPHONATES (MES) PRODUCERS AND PRODUCTION CAPACITY IN 2012

\begin{tabular}{lcc}
\hline \multicolumn{1}{c}{ Companies } & Location & Annual capacity (t) \\
\hline Lion ECO Chemicals Sdn Bhd & Malaysia & 25000 \\
KL Kepong Oleomas & Malaysia & 50000 \\
Guangzhou Keylink Chemical Co. & China & 40000 \\
Stepan & USA & 50000 \\
USA Huish Detergent Inc. & USA & 80000 \\
Dersa, Bogota & Colombia & 15000 \\
Lion Corporation & Japan & 40000 \\
Zhejiang Zanyu Technology Co., Ltd. & China & 60000 \\
Guangzhou Langqi & China & 36000 \\
Shandong Zoupingfuhai & China & 30000 \\
Shandong Jinlun & China & 60000 \\
Jiangsu Haiqing & China & 100000 \\
PT Wilmar Nabati, Gresik & Indonesia & 50000 \\
\hline
\end{tabular}

Source: Zulina (2013). 
developed by MPOB. Later, the findings may be used as a marketing tool to promote the utilisation of palm-based MES globally.

\section{METHODOLOGY}

\section{Scope, Functional Unit and System Boundary}

The scope of this study covers the LCA of palm-based MES production at the pilot plant scale, located in MPOB. The goal of this study is to evaluate the potential environmental impacts from the production of palm-based MES at pilot plant scale and also to find solutions or alternatives to reduce the impacts, where possible. The functional unit of this study is $1 \mathrm{t}$ of palm-based MES. The study covers both life cycle inventory (LCI) and life cycle impact assessment (LCIA). The system boundary used is cradle-to-gate as shown in Figure 1. The starting point is at the germination of oil palm seed and seedling maintenance at the nursery stage and ends at the production of MES.

Data sources for this study as listed in Table 2, which includes oil palm germinated seed production until MES production at pilot plant.

\section{Inventory Data}

The study was carried out at MPOB's MES pilot plant with $20 \mathrm{~kg} \mathrm{hr}^{-1}$ capacity. All wastes and emissions from this production were taken into consideration for impact assessment quantification. The entire inventory data were based on trials carried out at the pilot plant. These inventory data were collected for the duration of three years. This study included all the feedstock, chemicals, energy, water, emissions and wastes that had been used and produced during the production of MES. Inventory data for methyl ester were obtained from commercial methyl ester producer in Selangor, Malaysia. However, data on by-products produced from the production, i.e. ole-
TABLE 2. SOURCES OF INVENTORY DATA FOR METHYL ESTER SULPHONATES (MES) STUDY

\begin{tabular}{ll}
\hline \multicolumn{1}{c}{ Life cycle stage } & \multicolumn{1}{c}{ Data source } \\
\hline Oil palm nursery & Halimah et al. (2010) \\
Oil palm plantation & Zulkifli et al. $(2010)$ \\
Palm oil mill & Vijaya et al. (2010) \\
Fractionation of palm product & Tan et al. (2010) \\
Methyl ester & Commercial plant, \\
& Malaysia \\
MES & Pilot plant (MPOB, \\
& Malaysia) \\
\hline
\end{tabular}

um and methanol condensate, were self-generated as no data were available in the database. All relevant background data, such as energy, transport and auxiliary materials were taken from the database of the SimaPro software.

\section{Life Cycle Inventory}

Life cycle inventory (LCI) data are inventory data that have been calculated to quantify the environmental inputs and outputs of the functional unit within the system boundary. Input data required are material or energy that goes into the unit process and outputs are emissions that leave the unit process. Data used in this study were combination of primary and secondary data. Primary data were obtained during the actual plant production such as raw materials, wastes and energy consumption. Secondary data were related to the processes used, for example manufacturing of raw materials, and some of these data were derived from Ecoinvent database. The chain of the main life cycle stages in the production of MES includes the production of feedstock (methyl ester) and also manufacturing of raw materials and chemicals. Electricity was generated at power stations, where fossil fuels are consumed and wastes are generated. The electricity

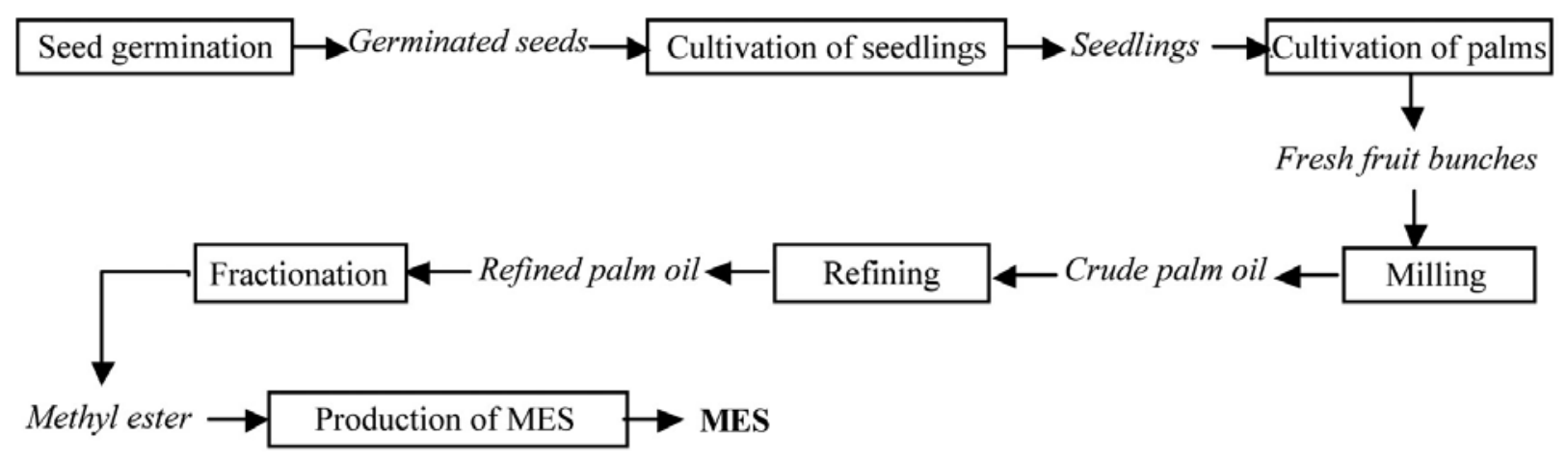

Figure 1. System boundary of methyl ester sulphonates (MES) production at pilot plant scale. 
process flow was identified from mining and extraction of fossil fuel, processing, production and distribution to the grid at the points of use.

\section{Life Cycle Impact Assessment}

Information from the inventory is then used for life cycle impact assessment (LCIA) study. Potential contributions of the inventory to various environmental effects are calculated and the potentials for impacts on the environment, the working environment and resources consumption are weighted in relation to one another in order to increase the sustainability of the inventory as a basis for decisions. For this study, SimaPro software version 8.0.2 with Eco-indicator 99 as methodology and Ecoinvent database were used to assess the LCIA of MES production. In this study, 11 of the impact categories were considered, i.e. carcinogens, respiratory organics, respiratory inorganics, climate change, radiation, ozone layer, ecotoxicity, acidification, land use, mineral and fossil fuels.

\section{Limitation of the Study}

The system boundary excludes the production of capital goods, e.g. machinery, buildings, vehicle manufacturing, vehicle maintenance and disposal, transport infrastructure and waste treatment.

\section{Sensitivity Analysis}

The sensitivity analysis in the LCA study is carried out in order to investigate changes in calculation of the total result of the LCA by assigning different values of the key figures in the study, while all other assumptions are unchanged. The variation in the key figures was chosen on the basis of the uncertainty with which they are burdened. According to the ISO 14044:2006 (E), sensitivity analysis is a procedure to determine how changes in data affect the results of the LCIA (ISO, 2006). The sensitivity analysis was carried out on the production of MES using this scenario, i.e. the production of MES using continued land use (oil palm to oil palm) with biogas emissions at the palm oil mill (cradle-to-gate) for MES production.

\section{RESULTS AND DISCUSSION}

\section{Life Cycle Inventory}

For MES production, all processes during the production (sulphonation, digestion, bleaching, neutralisation and drying) were included in this study. This LCI data were then weighted with respect to the functional unit in this study, which is $20 \mathrm{~kg} \mathrm{hr}^{-1}$ of MES production, and will be projected to $1 \mathrm{t}$ in the LCIA calculation. However, for this study, the production data are confidential and the discussion only focused on reporting the impact categories generated from the MES production towards the environment. Table 3 shows the LCI of MES produced at the pilot plant scale $\left(20 \mathrm{~kg} \mathrm{hr}^{-1}\right)$ including energy and water.

Data on wastes and emissions were verified based on one year data collection. Data on steam was calculated as steam and different from the total water used in order to avoid double counting on impacts later. Energy used is in the form of electricity from the national grid. For this study, the electricity data employed were from the Malaysian electricity profile. In pilot plant process, steam was generated from the boiler that used electricity as source of heat. The data validation procedure was carried out via on-site and actual measurements.

\section{Life Cycle Impact Assessment}

The characterisation, single score and weighted results are shown in Figures 2, 3 and 4, respectively. Figure 2 shows the contribution of each material used in the production including the energy and wastes generated from the process. Production of

TABLE 3. LIFE CYCLE INVENTORY (LCI) FOR METHYL ESTER SULPHONATES (MES) PRODUCED AT PILOT PLANT SCALE

\begin{tabular}{ll}
\hline Inputs & Source of data \\
\hline Methyl ester & Inventory \\
Sulphur dioxide & Inventory \\
Sodium hydroxide & Inventory \\
Hydrogen peroxide & Inventory \\
Methanol & Inventory \\
Air & Inventory \\
Electricity & Malaysian data (SIRIM) \\
Water & Inventory \\
Steam & Inventory \\
Nitrogen & Inventory \\
Catalyst & Inventory \\
\hline Outputs & Source of data \\
\hline Methyl ester sulphonates & Inventory \\
Oleum & Inventory \\
Sulphur dioxide (emission) & Inventory \\
Sulphur trioxide (emission) & Inventory \\
Waste water & Inventory \\
Waste methanol & Inventory \\
\hline
\end{tabular}




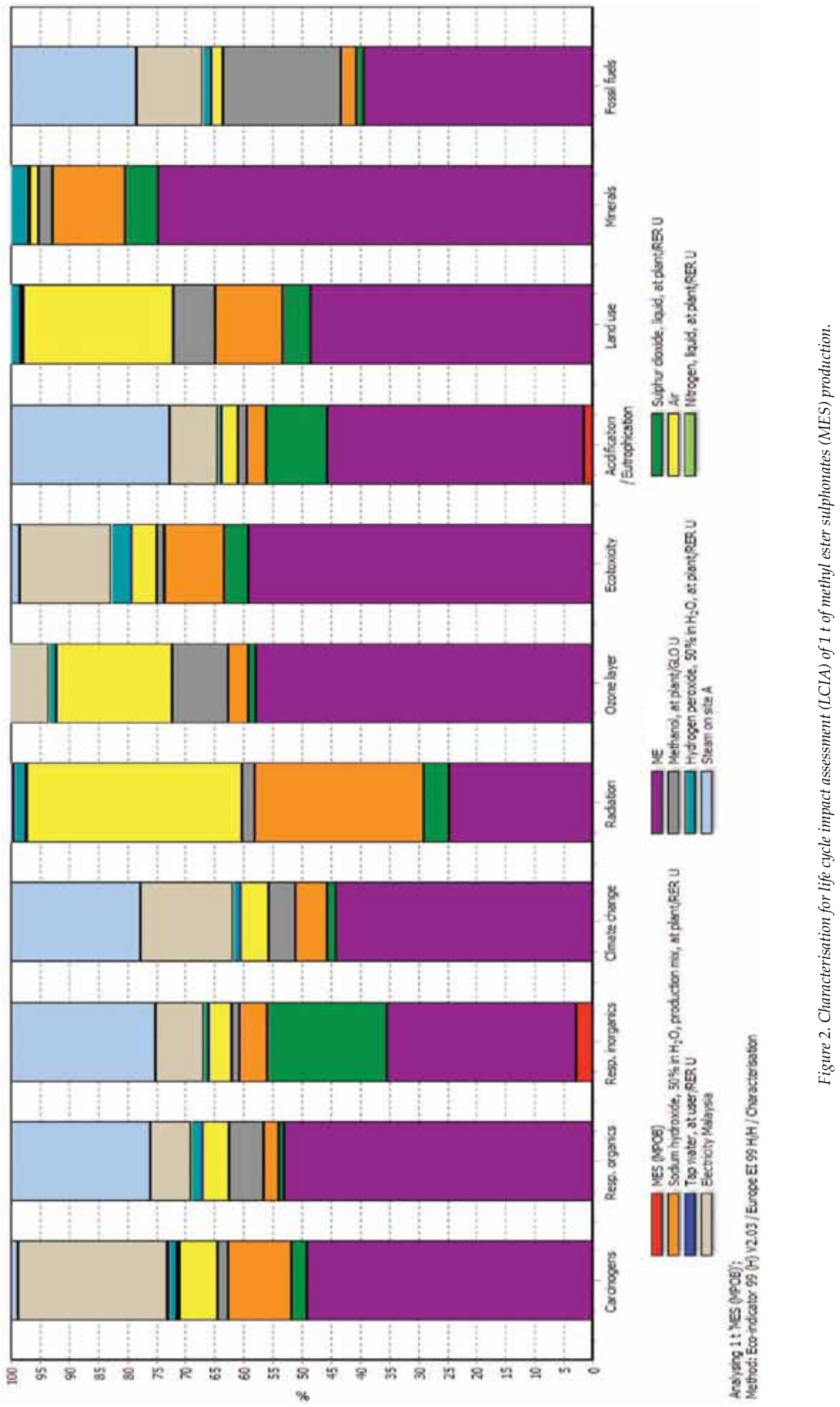




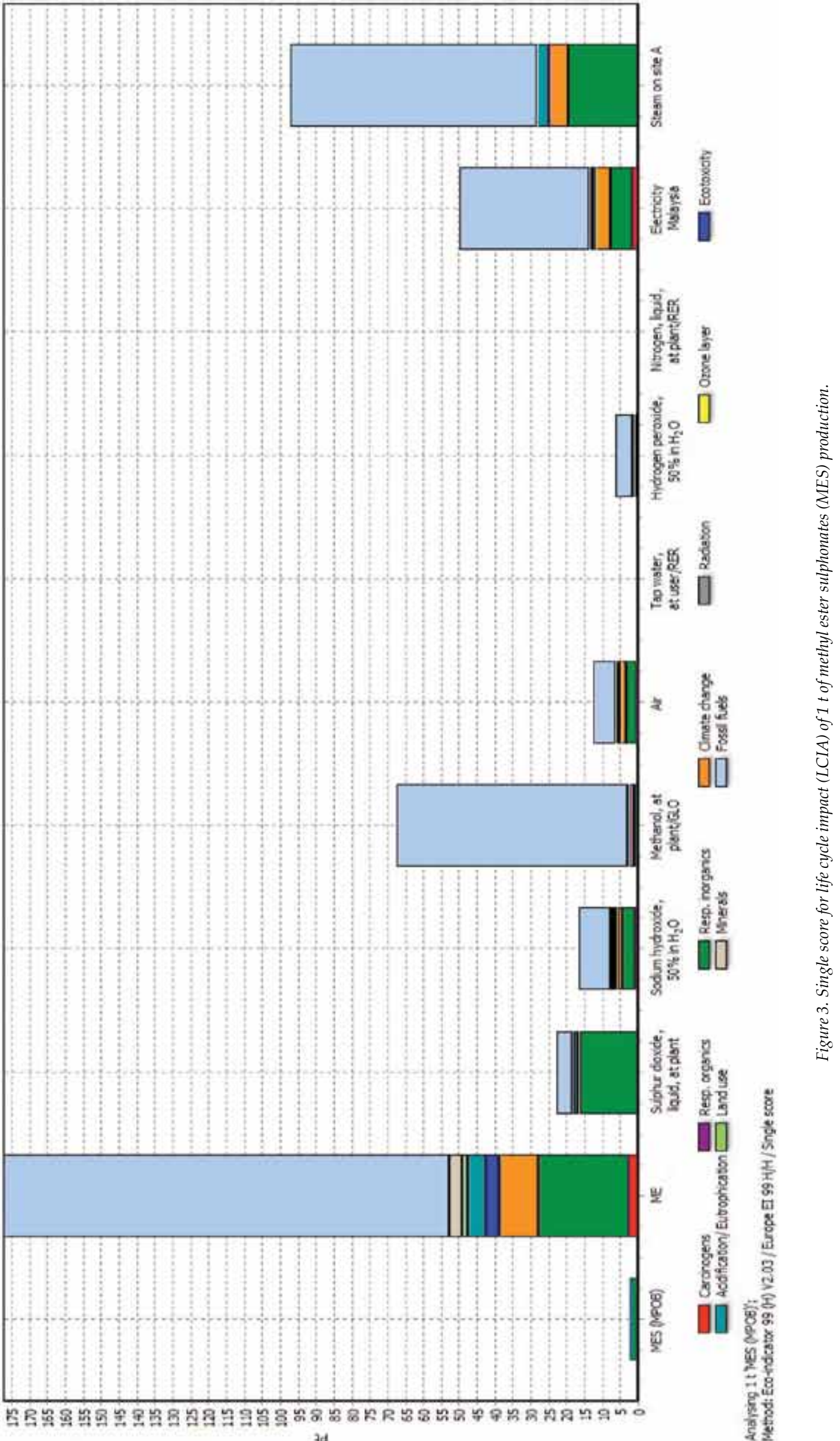




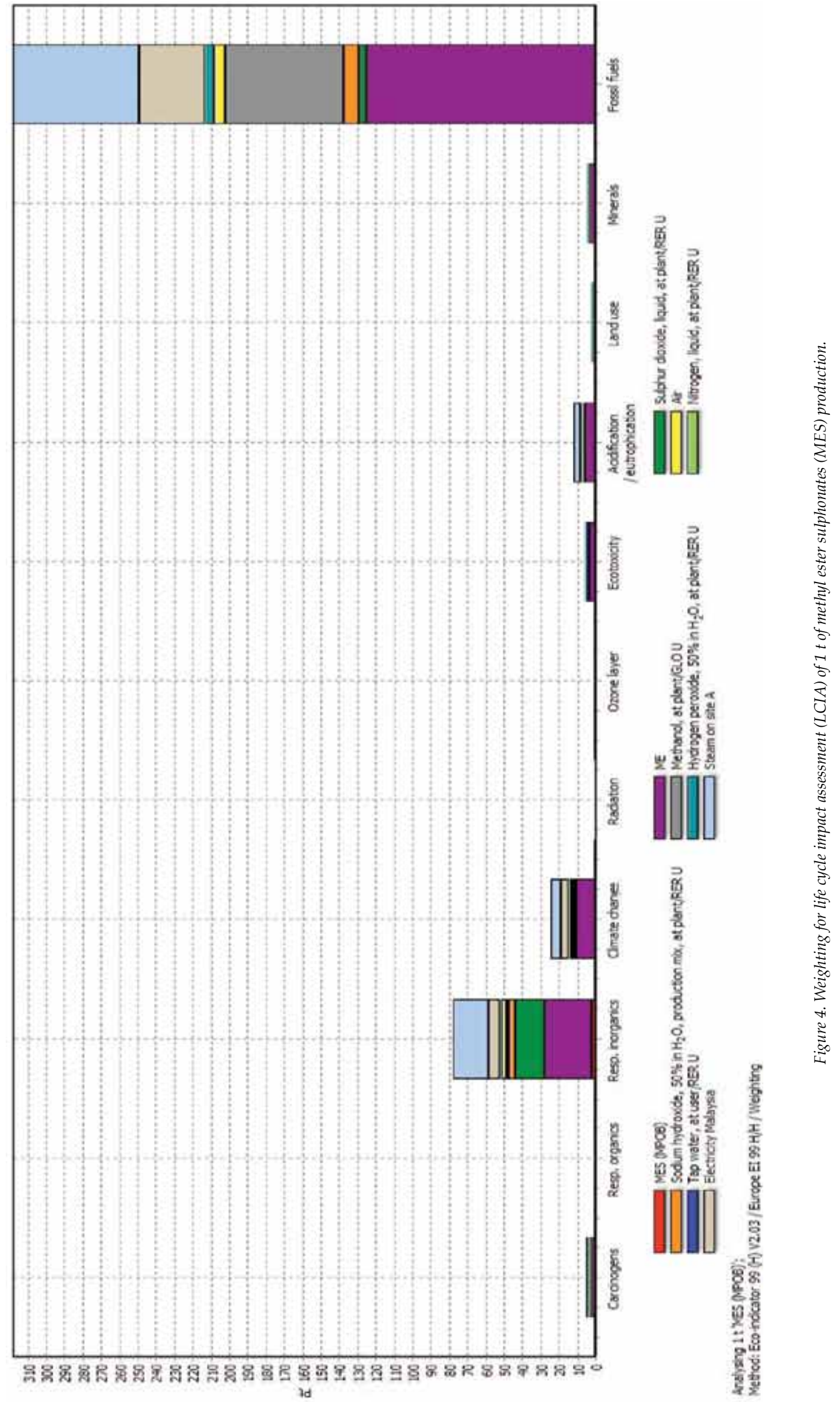


methyl ester that was used as feedstock contributed significant environmental impact towards almost all impact categories except for radiation, and also responsible as the main contributor for all these impact categories.

The single score results showed the main impact contributors for MES production were from production of methyl ester, steam, methanol and electricity (Figure 3). Sodium hydroxide and air contributed lower impacts during the production. All of the above environmental impact contributors were used as feed materials for MES production. Production of methyl ester contributed the highest impact because the production and activities at the upstream level were included in the analysis, i.e. refined bleached deodorised palm stearin. This is followed by steam where the impact was due to the utilisation of fossil material to produce steam, which in this case, electricity was used to produce steam for the plant boiler. Since electricity itself is produced from non-renewable resources, it contributed the highest impact on fossil fuels impact category and is reflected through steam production. It can be concluded that the impact from steam was contributed by the production of electricity, and not from the steam consumption at the plant. The impact from wastes and emissions as output parameters from the production were small compared to the impact from the input parameters. The emission contributed by sulphur dioxide was only $0.02 \%$ from the total impacts generated during MES production.

The weighted results showed that the significant impact categories in MES production were fossil fuels, respiratory inorganics and climate change (Figure 4). The impact on fossil fuels category was contributed mainly by the production of methyl ester (used as feedstock to produce MES), steam, methanol and electricity. As mentioned previously, the highest impact on fossil fuels was caused by the production of methyl ester where the impact mainly contributed from the upstream activities in order to produce the feedstock. The impact on respiratory inorganics category was mostly contributed by methyl ester and steam that were used to produce MES. The main air emissions generated was from the production of feedstock.

Letchumi and Sumiani (2014) found that the main impacts in MES production were land use and respiratory inorganics. However, in our study, there is no significant impact on land use category since this study was conducted using the best practice currently being implemented in the oil palm plantation in Malaysia, which is continued land use. Apart of that, Michael et al. (2007) had reported that resource and energy consumption as well as emissions for the surfactant based on palm oil were clearly more favourable than for the one being produced from fossil feedstock.

\section{Sensitivity Analysis}

This LCA study does not only focus on the design, process or finish product, but also on the life cycle stage of feedstock used to produce the product. The sensitivity analysis can determine how the final results are affected by changing the production feedstock. It is well-known that in Malaysia, all the plantations are from continued land use and no more logged over forest being converted to oil palm plantation. However, as of October 2014, only $16 \%$ of the palm oil mills have implemented biogas capture facility/system (Loh et al., 2014). Thus, this sensitivity analysis was carried out to determine the effect of not using biogas capture facility at palm oil mill stage to produce feedstock for MES production, in this case refined beached deodorised palm stearin (RBDPS) feedstock for methyl ester production. So, this kind of process will contribute biogas emissions towards environment. By considering this scenario, the sensitivity analysis was carried out for palmbased MES production using continued land use at the plantation and biogas emissions at the palm oil mill.

The sensitivity analysis scenario was compared with the base case scenario for palm-based MES production as conducted previously. The weighting result is shown in Figure 5. The system boundary includes:

- oil palm nursery;

- oil palm plantation (oil palm to oil palm);

- palm oil mill (with biogas emissions);

- refinery;

- methyl ester plant (data obtained from the methyl ester producer); and

- MES production.

From the sensitivity analysis, it was found that the biogas emissions from the palm oil mill can increase the intensity of the impact for all impact categories, i.e. fossil fuels, respiratory inorganics and climate change. By using the biogas capture facility as in base case study, it can help reduce the impact in all impact categories. The reduction in the impacts value by implementation of biogas capture facility in the mills was more than $48 \%$ compared to without using the same facility in the mill. Even though this impact is more related to the mill, but since the cradle-to-gate assessment was carried out for this production, therefore this impact also need to be considered and be taken as a part of the impact for the whole MES production.

\section{CONCLUSION}

The findings of this study were calculated based on Eco-indicator 99 methodology and the system 


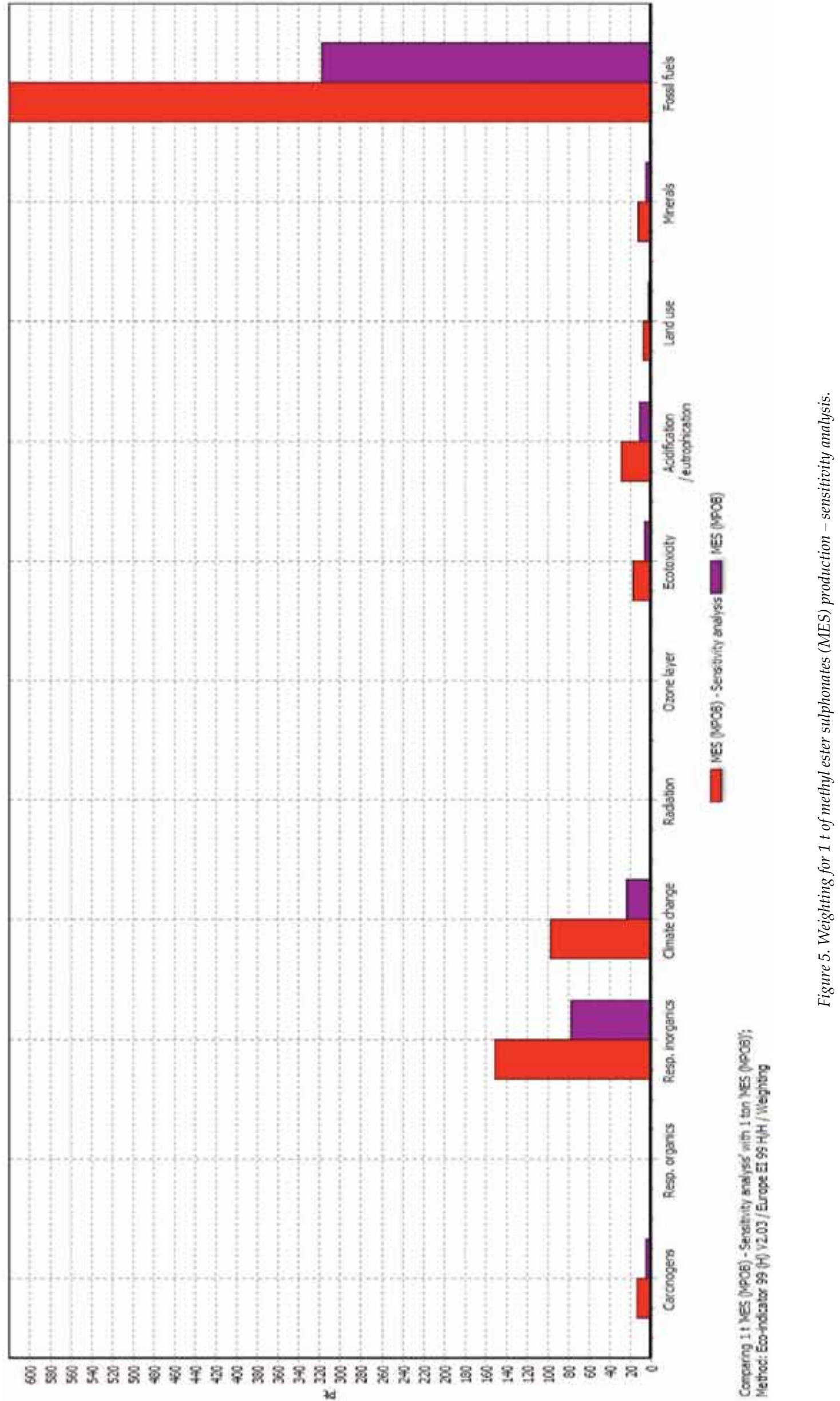


boundary was from oil palm nursery to MES production using continued land use and biogas capture scenario. Based on the results, the most significant impacts from MES production were fossil fuels, respiratory inorganics and climate change. These impacts were directly contributed by the production of methyl ester, steam and methanol that were used in the MES production. In sensitivity analysis, it was proven that by using biogas capture facility in the palm oil mill, it can help to reduce more than $48 \%$ impact value of fossil fuels, respiratory inorganics and climate change impact categories. Based on the findings of this study, there was no significant impact on land use category and the sustainable production of MES can be achieved by using MPOB pilot plant with best practice implemented in palm oil industry. As a recommendation, palm-based MES can be the best alternative to replace petrol-based surfactant in the detergent formulation due to environmental concern and can help the detergent industry to reduce the reliance on the fossil fuel resources.

\section{ACKNOWLEDGEMENT}

The authors would like to thank the Director-General of MPOB for permission to publish this article. Thanks are also extended to the MES production team of the Advanced Oleochemical Technology Division, MPOB. The authors would also like to express their gratitude to the methyl ester producers in Malaysia [Malaysian Oleochemical Manufacturers Group (MOMG)] for their data on the methyl ester production which was required to complete this LCA study.

\section{REFERENCES}

GRAND VIEW RESEARCH INC. (2014). Global biosurfactants market by product (rhamnolipids, sophorolipids, MES, APG, sorbitan esters, sucrose esters) expected to reach USD 2308.8 million by 2020. Accessed on 18 November 2014.

HALIMAH, M; ZULKIFLI, H; VIJAYA, S; YEW, A T; PUAH, C W and CHOO, Y M (2010). Life cycle assessment of oil palm seedling production (part 1). J. Oil Palm Res. Vol. 22: 878-886.

INTERNATIONAL ORGANISATION FOR STANDARDIZATION (2006). ISO 14044: Environmental Management - Life Cycle Assessment Requirements and Guidelines. Geneva.

LETCHUMI, T and SUMIANI, Y (2014). Comparative analysis of environmental evaluation of LAS and MES in detergent - a Malaysian case study. World Applied Sciences J. Vol. 31: 1635-1647.

LOH, S K; NASRIN, A B; MOHAMAD AZRI, S; MUZZAMMIL, N; NURUL ADELA, B; DARYL, $\mathrm{J}$ T; STASHA, E R A; LIM, W S and CHOO, Y M (2014). Biogas update under palm oil National Key
Economic Area (NKEA) Entry Point Project, EPP 5. Paper presented at the POMREQ 2014, 3-4 October 2014, Kuching, Sarawak.

MICHAEL, A R M; JÜRGEN, O M and ULRICH, S S (2007). Plant oil renewable resources as green alternatives in polymer science. Chemical Society Reviews, 36: 1788-1802.

PUAH, C W; CHOO, Y M and MA, A N (2010). Life cycle assessment for the production and use of palm biodiesel (part 5). J. Oil Palm Res, Vol 22: 927-933.

RAZMAH, G; ZULINA, A M; PARTHIBAN, S; MOHTAR, Y and SALMIAH, A (2006). Assessment of aquatic effects of palm-based alpha-sulphonated methyl ester (SME). J. Oil Palm Res. Vol. 18: 225-230.

RAZMAH, G and SALMIAH, A (2004). Biodegradability and ecotoxicity of palm stearinbased methyl ester sulphonates. J. Oil Palm Res. Vol. 16 (1): 39-44.

SALMIAH, A; ZAHARIAH, I and JASMIN, S (1998). Palm-based sulphonated methyl esters and soap. J. Oil Palm Res. Vol. 10 (1): 15-35.

VIJAYA, S; CHOO, Y M; HALIMAH, M; ZULKIFLI, H; YEW, A T and PUAH, C W (2010). Life cycle assessment of the production of crude palm oil (part 3). J. Oil Palm Res. Vol. 22: 895-903.

VIJAYA, S; CHOO, Y M; HALIMAH, M; ZULKIFLI, H; YEW, A T and PUAH, C W (2010). Life cycle assessment of the production of crude palm kernel oil (part 3a). J. Oil Palm Res. Vol. 22: 904-912.

YEW, A T; HALIMAH, M; ZULKIFLI, H; VIJAYA, S; PUAH, C W; CHONG, C L; MA, A N and CHOO, Y M (2010). Life cycle assessment of refined palm oil production and fractionation (part 4). J. Oil Palm Res. Vol. 22: 913-926.

YUTAKA, A (2009). MES next generation of anionic surfactant, its production and application in laundry detergent. Paper presented at the $9^{\text {th }}$ Asia Surfactant, 24-25 September 2009, Shanghai, China.

ZULINA, A M (2013). Challenges in formulating detergent with palm-based MES. Paper presented at the PIPOC 2013 International Palm Oil Congress, 1921 November 2013, KLCC, Kuala Lumpur.

ZULINA, A M; RAZMAH, G; PARTHIBAN, S; ZAHARIAH, I and SALMIAH, A (2006). Alphasulphonated methyl ester as an active ingredients in palm-based powder detergent. J. Surfactants and Detergents Vol. 9 (2): 161-167.

ZULKIFLI, H; HALIMAH, M; CHAN, K W; CHOO, Y M and MOHD BASRI, W (2010). Life cycle assessment for oil palm fresh fruit bunch production from continued land use for oil palm planted on mineral soil (part 2). J. Oil Palm Res. Vol. 22: 887-894. 